\title{
Environmental factors influencing the seasonal dynamics of spring algal blooms in and beneath sea ice in western Baffin Bay
}

Oziel L ${ }^{1,2}$, P. Massicotte ${ }^{1}$, A. Randelhoff ${ }^{1}$, J. Ferland ${ }^{1}$, A. Vladoiu ${ }^{3}$, L. Lacour ${ }^{1}$, V. Galindo ${ }^{4,6}$, S. LambertGirard $^{1}$, D. Dumont ${ }^{4}$, Y. Cuypers ${ }^{3}$, P. Bouruet-Aubertot ${ }^{3}$, C-J Mundy ${ }^{6}$, J. Ehn $^{6}$, G. Bécu ${ }^{1}$, C. Marec ${ }^{1,5}$, M-H Forget $^{1}$, N. Garcia ${ }^{7}$, P. Coupel ${ }^{7}$, P. Raimbault ${ }^{7}$, M-N Houssais ${ }^{3}$, M. Babin ${ }^{1}$

Affiliations:

${ }^{1}$ Takuvik Joint International Laboratory, Laval University (Canada) - CNRS (France), Département de biologie et Québec-Océan, Université Laval, Québec, Québec G1V 0A6, Canada

${ }^{2}$ Remote Sensing Unit, Bedford Institute of Oceanography, Fisheries and Oceans Canada P.O. Box 1006, Dartmouth, Nova Scotia, B2Y 4A2, Canada

${ }^{3}$ Sorbonne Université (UPMC, Paris6)/CNRS/UPMC/IRD/MNHN, Laboratoire d'Océanographie et du Climat (LOCEAN), Institut Pierre Simon Laplace (IPSL), 75252 Paris Cedex 05, France

${ }^{4}$ Institut des sciences de la mer de Rimouski, Université du Québec à Rimouski, 310 Allée des Ursulines, Rimouski, Québec G5L 3A1, Canada

${ }^{5}$ Laboratoire d'Océanographie Physique et Spatiale, UMR 6523, CNRS - IFREMER - IRD -UBO, Plouzané, France

${ }^{6}$ Centre for Earth Observation Science, University of Manitoba, Winnipeg, Manitoba R3T 2N2, Canada ${ }^{7}$ Aix-Marseille University, Mediterranean Institute of Oceanography (MIO), UMR7294, CNRS/INSU, UMR235, IRD, Marseille, CEDEX 09, France

*Corresponding author’s email address: laurent.oziel@takuvik.ulaval.ca, 


\section{Introduction}

This supporting information provides additional analysis and details that are not crucial for the global understanding. This information will, however, help the reader throughout the manuscript by giving more contextualization. 


\section{List of Contents:}

Figure S1. 'True color' Landsat 8 Snapshots of the study site area in 2015. The study site is located in the red circle. Melt ponds are detectable by their clear blue color; dark areas indicate open waters and make cracks in the ice visible. Darker sea ice such as on 21 July provides evidence that melt ponds have been flushed from the top of the sea ice.

Figure S2. 'True color' Sentinel-2 Snapshots of the study site area in 2016. The study site is located in the red circle. Melt ponds are detectable by their clear blue color; dark areas indicate open waters and make cracks in the ice visible. Darker sea ice such as on 19 July provides evidence that melt ponds have been flushed from the top of the sea ice.

Figure S3. Time series of ANP “Arctic N-P relationship" based on nutrient sampling. A high (low) ANP in blue (red) indicates a major Pacific (Atlantic) Water, PW (AW), contribution for year 2015 (top) and 2016 (bottom). Dates are day/month.

Figure S4. Winter (late April) 'baseline' of the vertical hydrographic structure. Profiles from 2015 (upper) and 2016 (lower) of conservative temperature $\left({ }^{\circ} \mathrm{C}\right.$, left), absolute salinity $\left(\mathrm{g} \mathrm{kg}^{-1}\right.$, middle) and potential density anomaly $\left(\mathrm{kg} \mathrm{m}^{-3}\right.$, right). $\mathrm{TCW}=$ thermocline waters; $\mathrm{MLD}=$ winter mixed layer depth based on a $\Delta \sigma=0.1 \mathrm{~kg} \mathrm{~m}^{-3}$ criterion from Peralta-Ferriz and Woodgate (2015); WCHW = Winter Cold Halocline Water following definition from Rudels et al. (1996).

Figure S5. Two-year time series of air temperature, wind speed, sea ice concentration, and daily total precipitation. Shown are 7-day running averages of (A) air temperature $\left({ }^{\circ} \mathrm{C}\right)$ (Qikiqtarjuaq airport) (B) wind speed $\left(\mathrm{km} \mathrm{h}^{-1}\right)$ (Qikiqtarjuaq airport) (C) sea ice concentration (\%) from AMSR-2 and (D) daily total precipitation in liquid water equivalent $(\mathrm{mm})$ (Qikiqtarjuaq airport). Knowing that snow density ranges between 0.1 and $0.8 \mathrm{~kg} \mathrm{~m}^{-3}$, the snow thickness could be estimated by multiplying the total liquid precipitation by a factor varying between 1.25 to 10 . Red dashed vertical line indicates 2 strong wind events considered as storms.

Figure S6. Winter air temperature anomalies. February air temperature anomalies at $2 \mathrm{~m}$ in 2015 and 2016 over the 1980-2016 mean. The red star indicates the study site. Source: http://nsidc.org/soac/temperature.html\#merra-temperature.

Figure S7. SAR images from Sentinel-1 of the southwestern Baffin Bay area. Area selected is close to the study site (red star). The evolution of the sea ice structure deformation was investigated using a single C-band (3.8-7.5 cm, 4-8 GHz) Synthetic Aperture Radar (SAR) from the Sentinel-1 satellite constellation (Dierking, 2013). The acquisition mode used was the Extra Wide mode Ground Range Detected Medium resolution (EW GRDM) which provided a definition of $40 \times 40 \mathrm{~m}$. The backscatter of the electromagnetic wave transmitted at horizontal polarization was received and decomposed into horizontal $(\mathrm{HH})$ and vertical (HV) polarization components. Only the "less noisy" HH component was used in the present study (Dierking, 2010). These images allow us to detect changes in ice surface roughness and to characterize different sea ice types (e.g., landfast ice, drifting ice), and open ocean areas like cracks and leads. Dark grey areas, such as the ones observed near the study site, suggest smooth landfast sea ice that is not affected by rafting or ridges (bright grey). Two particular events were detected: (1) almost all sea ice was lost by mid-November 2014 compared with 2015; and (2) the sea ice broke up on 11 December 2014, and drift ice and open water areas appeared. A week later, almost no open water remained detectable and the sea ice was consolidated. 
Figure S8. Time series of transmittance, snow thickness and ice algal concentration. For 2015 (top) and 2016 (bottom) time series transmittance (\%) was derived from daily PAR converted to $\mathrm{W} \mathrm{m}^{-2}$, and is shown together with snow thickness $(\mathrm{m})$ and ice algal concentration in the bottom 0-3 cm (TChla $a_{0-3 \mathrm{~cm}}, \mathrm{mg}$ $\mathrm{m}^{-2}$ ) of sea ice. Dates are day/month.

Figure S9. Hydrographic temporal evolution of the entire water column. Time series of (A) in situ current velocities at 10-m depth in black and predicted from harmonic analysis in red line, (B) conservative temperature $\Theta\left({ }^{\circ} \mathrm{C}\right)$ and $(\mathrm{C})$ absolute salinity $\mathrm{S}_{\mathrm{A}}\left(\mathrm{g} \mathrm{kg}^{-1}\right)$ fields with super-imposed isopycnals of potential anomaly density $\left(\mathrm{kg} \mathrm{m}^{-3}\right)$ in white lines. (D) Brunt-Väisälä frequency $\mathrm{N}^{2}\left(\mathrm{~s}^{-2}\right)$ and (E) Turner angle $\left(^{\circ}\right)$ until $340 \mathrm{~m}$. Turner angles $>0^{\circ}$ indicates that temperature is the main contributor to the density gradient whereas angles $<0^{\circ}$ indicate that salinity is the main contributor. Angles $<-45^{\circ}$ indicate that salinity is working against temperature. Vertical dotted lines chronologically represent snow melt initiation, melt pond initiation and sea ice breakup. The red dashed line indicates the date when turbulence was measured over a 13-h period. Dates are month/day.

Figure S10. Characterization of the dominant tidal waves. Harmonic analysis of the current at $10 \mathrm{~m}$ for (A) 2015 and (B) 2016. Vertical lines indicate the main harmonic oceanic tidal waves associated with unique frequencies and amplitudes. Here, the M2 wave (period $=12 \mathrm{~h} 25 \mathrm{~min}$ ) dominates the tidal signal.

Figure S11. Depth evolution of tidal currents magnitude and direction. Tidal variance ellipses for both years (2015 and 2016) at different depths from 10 to $38 \mathrm{~m}$ every $2 \mathrm{~m}$. The velocity constituent $\mathrm{U}(\mathrm{V})$ indicates the eastward (northward) direction.

Figure S12. Temporal evolution of nutrients in seawater. Time series of phosphate and silicate concentrations in the water column for 2015 (left) and 2016 (right). Dates are day/month.

Figure S13. Estimation of the depth integrated biomass bias from HPLC. Depth integration (A) Example of a TChla profile from HPLC pigment data (left) and a Chla profile from a fluorometer (right) on 27 May 2015. The horizontal dashed black line marks the depth of the deepest TChl $a$ measurement while the dashed grey line marks the depth where only $1 \%$ of the maximum value of the Chla profile remains. (B) Underestimate of biomass stock when the Chla is integrated down to the depth of the deepest TChl $a$ measurement rather than the depth of 1\% Chla, for 2015 (top) and 2016 (bottom). Horizontal dashed red lines mark the average underestimate. Dates in (B) are month/day.

Figure S14. Modelled synoptic circulation in Baffin Bay. Monthly maps of synoptic current velocity difference. (A) current velocities in 2015 (B) and in 2016 (C) from reanalysis at $50 \mathrm{~m}$ (GLORYS12V, CMEMS http://marine.copernicus.eu, id = GLOBAL_REANALYSIS_PHY_001_030). Maps of current velocity difference are smoothed with a 72-km standard deviation Gaussian filter to remove mesoscale activity. These maps are illustrating large-scale circulation differences between 2016 and 2015. The outflowing Baffin Island current (BIC) seemed to be more intense in 2016 carrying more Arctic Waters from Nares and Lancaster straits.

Figure S15. Closest distance between the study site and the sea ice edge. Sea ice edge was defined as sea ice concentration $=15 \%$. Dates are month/day.

Figure S16. Bulk salinity against in situ temperature across all sections of all ice cores. The black lines are lines of constant brine volume (given as the percentage of the total volume that brines occupy). Year 
2016 had remarkably higher temperatures, but the lower brine volumes observed at the bottom of the ice were due instead to differences in bulk salinity.

Figure S17. Phytoplankton accumulation rate. Accumulation rate $\left(\mathrm{d}^{-1}\right)$ was derived following the Boss and Behrenfeld (2010) calculation. The phytoplankton bloom initiation (vertical red dashed line) is identified when the accumulation rates are positive for one week. The snow melt onset is in black vertical dashed lines.

\section{References}




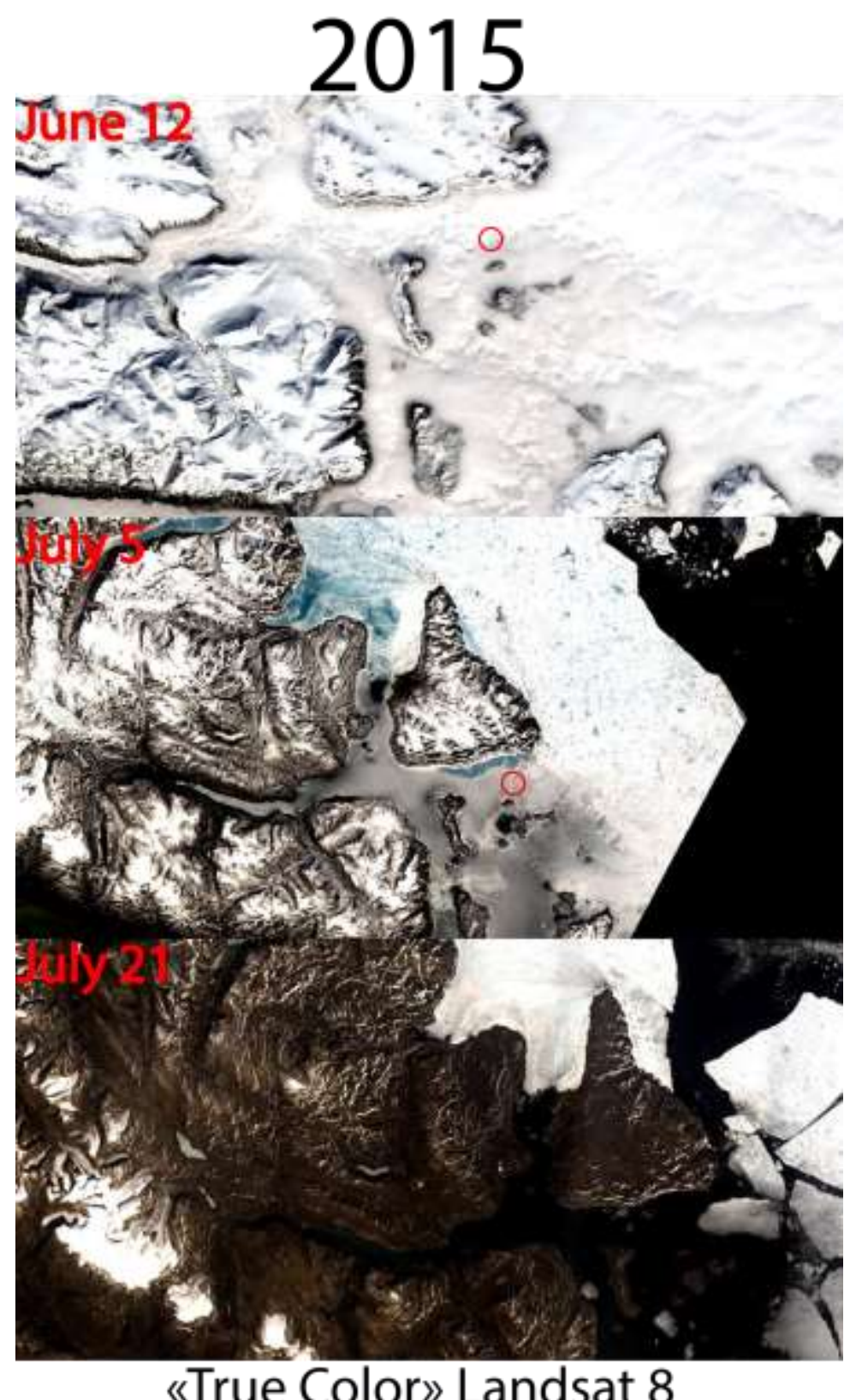

Figure S1. 'True color' Landsat 8 Snapshots of the study site area in 2015. The study site is located in the red circle. Melt ponds are detectable by their clear blue color; dark areas indicate open waters and make cracks in the ice visible. Darker sea ice such as on 21 July provides evidence that melt ponds have been flushed from the top of the sea ice. 


\section{6}

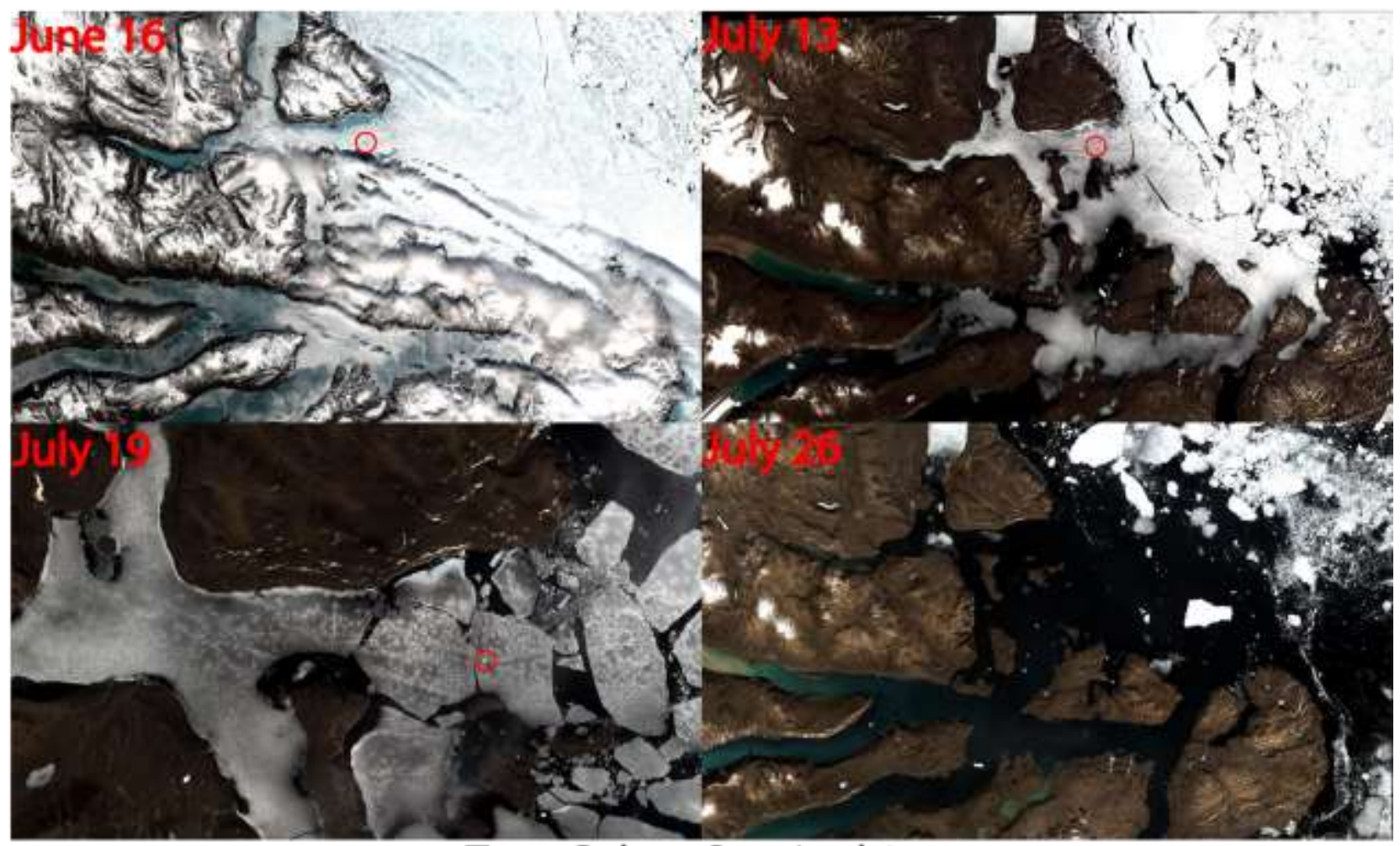

«True Color» Sentinel 2

Figure S2. 'True color' Sentinel-2 Snapshots of the study site area in 2016. The study site is located in the red circle. Melt ponds are detectable by their clear blue color; dark areas indicate open waters and make cracks in the ice visible. Darker sea ice such as on 19 July provides evidence that melt ponds have been flushed from the top of the sea ice. 


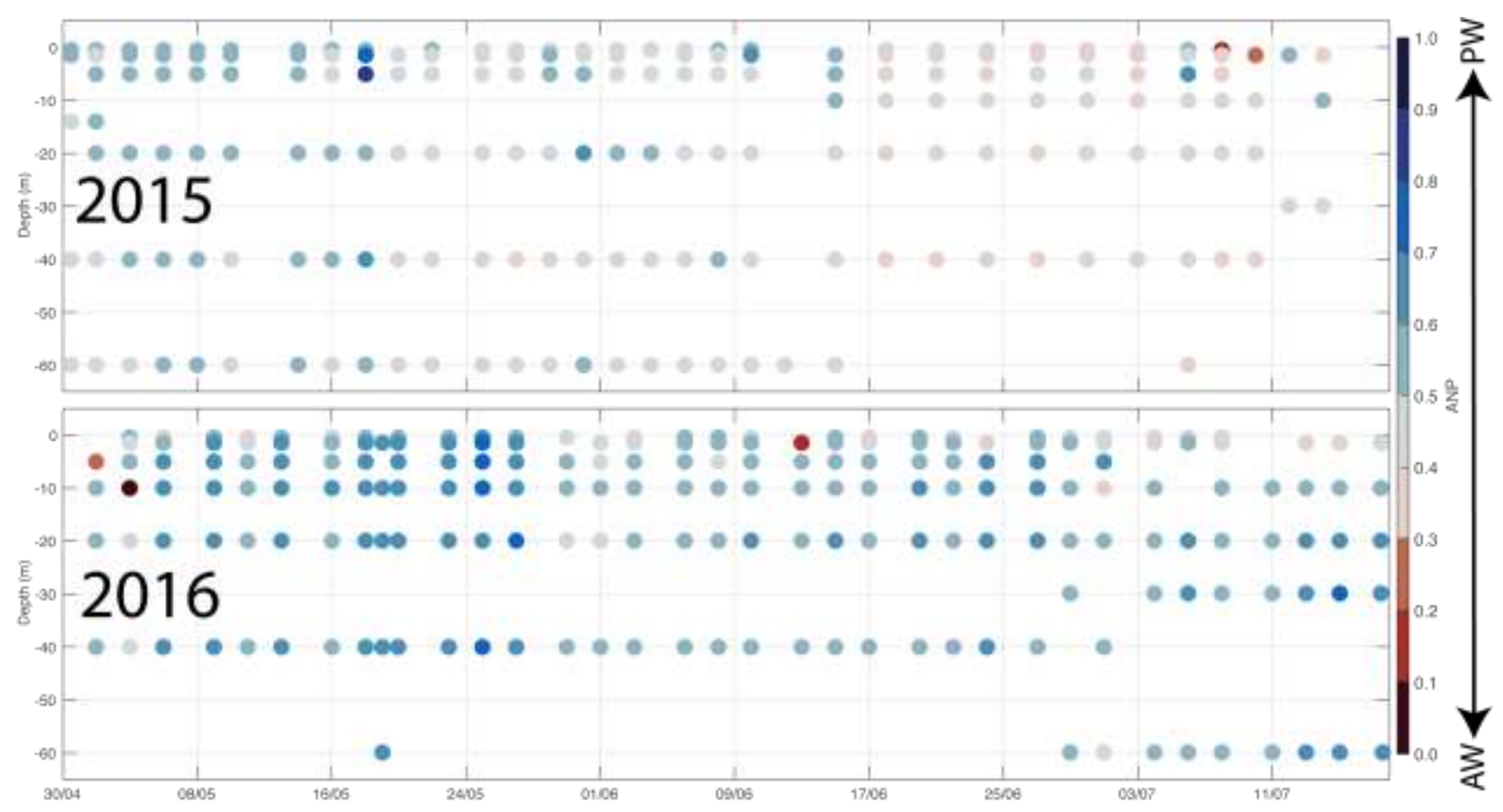

Figure S3. Time series of ANP "Arctic N-P relationship" based on nutrient sampling. A high (low) ANP in blue (red) indicates a major Pacific (Atlantic) Water, PW (AW), contribution for year 2015 (top) and 2016 (bottom). Dates are day/month. 

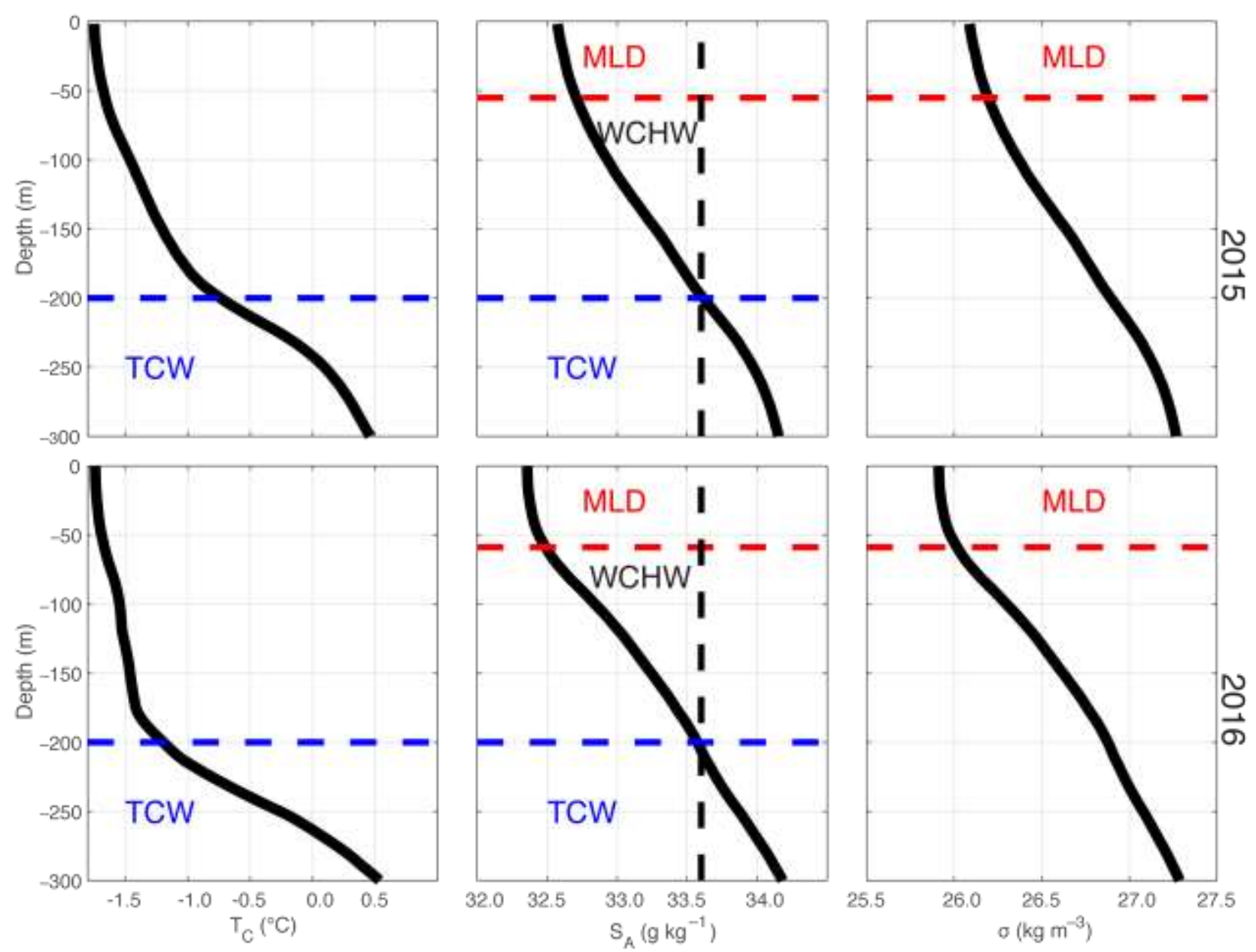

Figure S4. Winter (late April) 'baseline' of the vertical hydrographic structure. Profiles from 2015 (upper) and 2016 (lower) of conservative temperature $\left({ }^{\circ} \mathrm{C}\right.$, left), absolute salinity $\left(\mathrm{g} \mathrm{kg}^{-1}\right.$, middle) and potential density anomaly $\left(\mathrm{kg} \mathrm{m}^{-3}\right.$, right $) . \mathrm{TCW}=$ thermocline waters; $\mathrm{MLD}=$ winter mixed layer depth based on a $\Delta \sigma=0.1 \mathrm{~kg} \mathrm{~m}^{-3}$ criterion from Peralta-Ferriz and Woodgate (2015); WCHW = Winter Cold Halocline Water following definition from Rudels et al. (1996). 
A

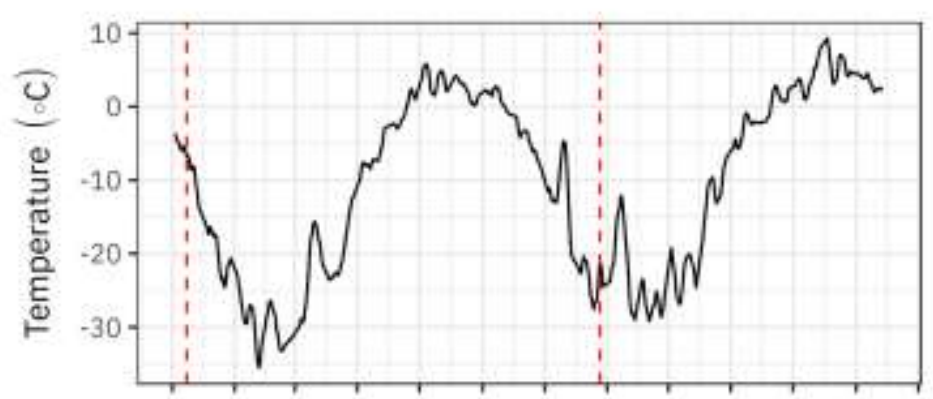

B

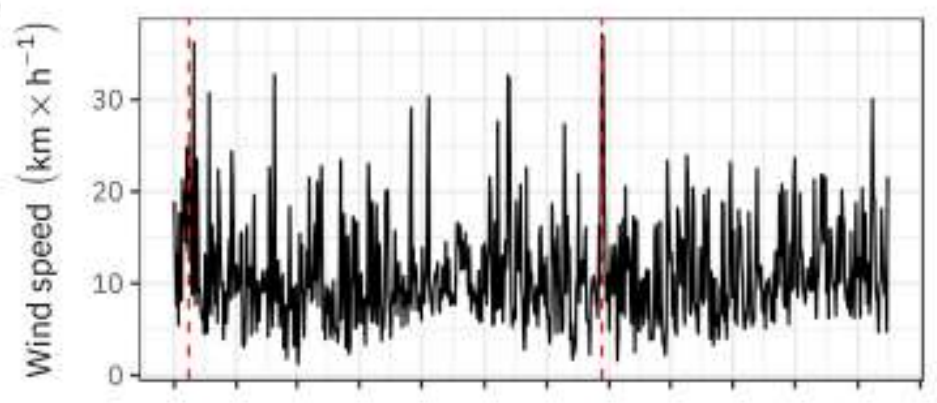

C
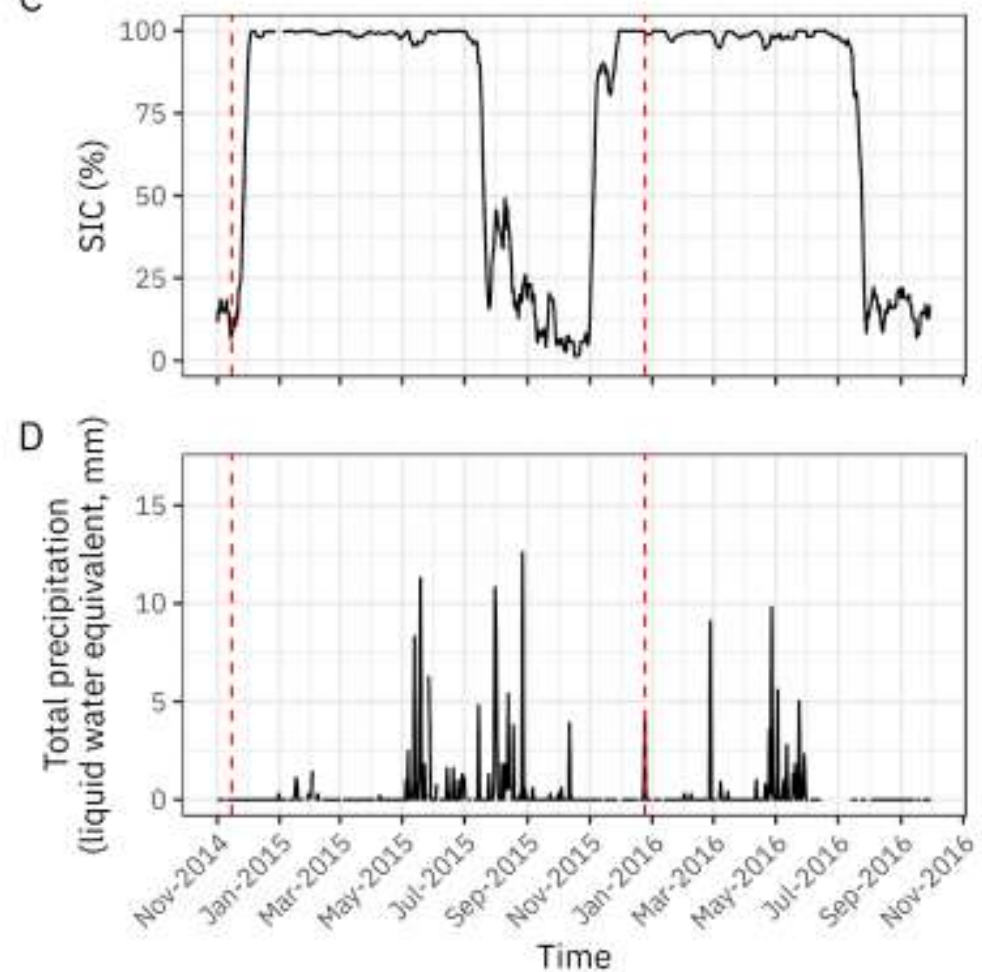

Figure S5. Two-year time series of air temperature, wind speed, sea ice concentration, and daily total precipitation. Shown are 7-day running averages of $(\mathrm{A})$ air temperature $\left({ }^{\circ} \mathrm{C}\right)$ (Qikiqtarjuaq airport) (B) wind speed $\left(\mathrm{km} \mathrm{h}^{-1}\right)$ (Qikiqtarjuaq airport) (C) sea ice concentration (\%) from AMSR-2 and (D) daily total precipitation in liquid water equivalent $(\mathrm{mm})$ (Qikiqtarjuaq airport). Knowing that snow density ranges between 0.1 and $0.8 \mathrm{~kg} \mathrm{~m}^{-3}$, the snow thickness could be estimated by multiplying the total liquid precipitation by a factor varying between 1.25 to 10 . Red dashed vertical line indicates 2 strong wind events considered as storms. 


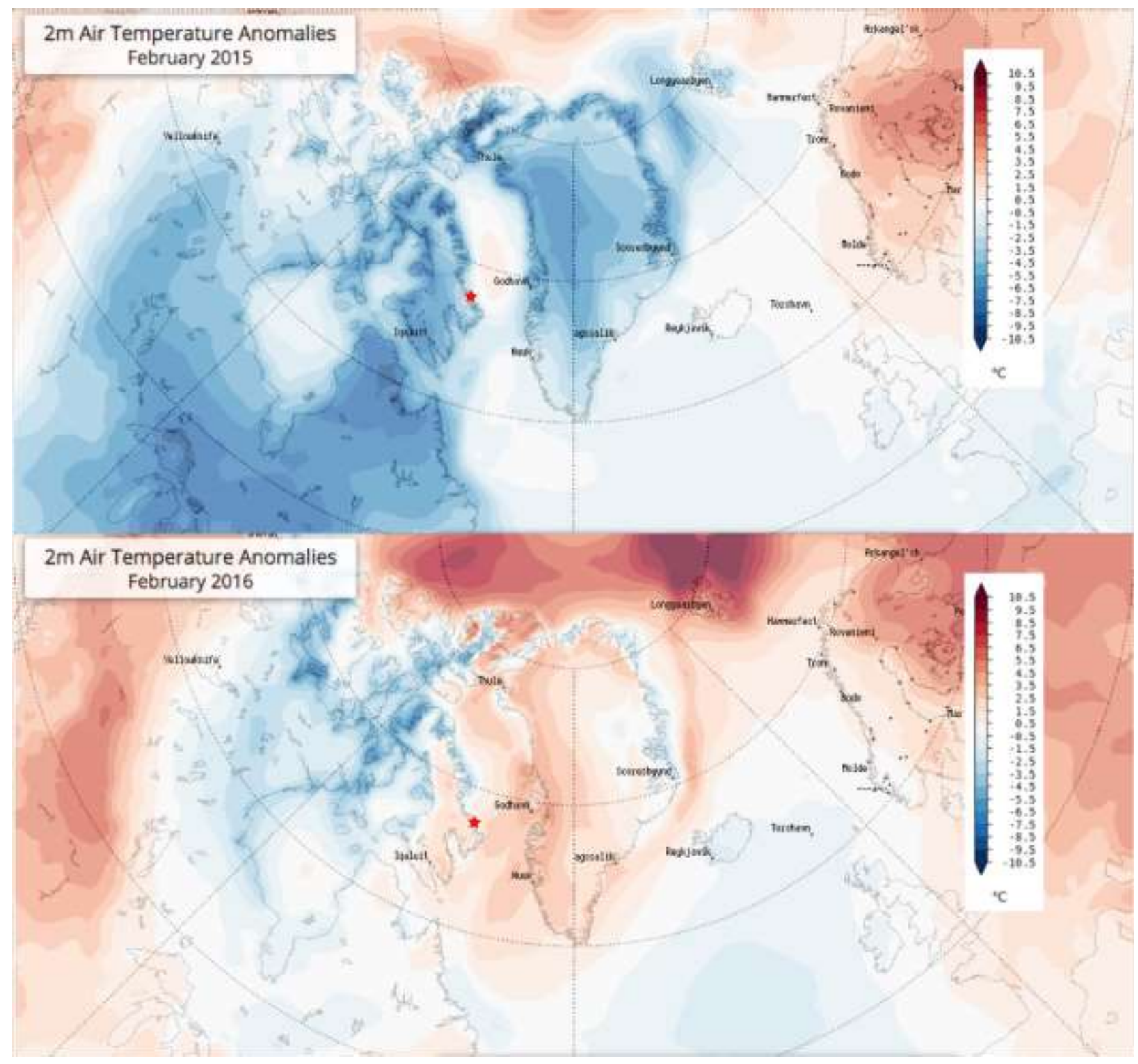

Figure S6. Winter air temperature anomalies. February air temperature anomalies at $2 \mathrm{~m}$ in 2015 and 2016 over the 1980-2016 mean. The red star indicates the study site. Source: http://nsidc.org/soac/temperature.html\#merra-temperature. 

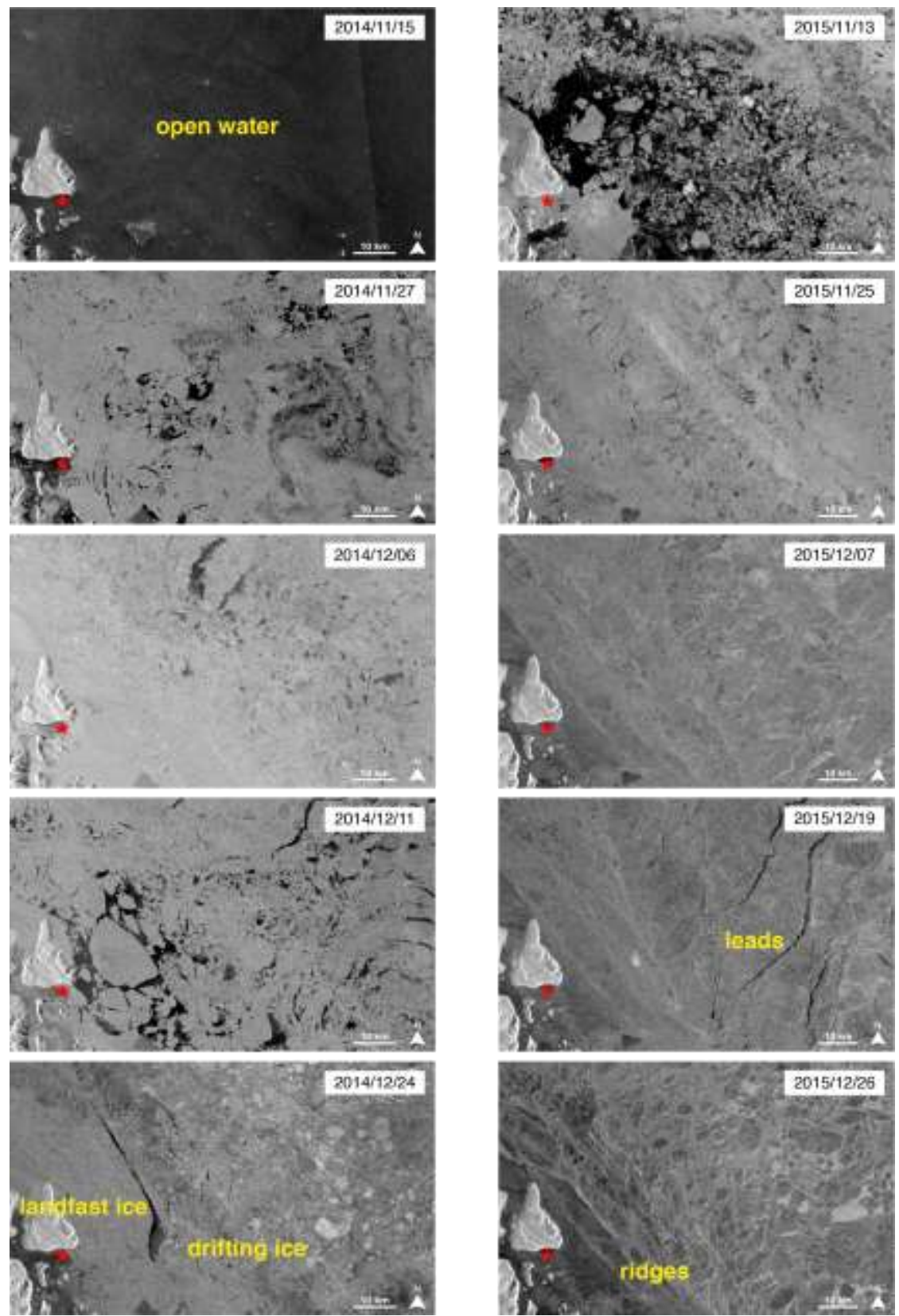

Figure S7. SAR images from Sentinel-1 of the southwestern Baffin Bay area. Area selected is close to the study site (red star). The evolution of the sea ice structure deformation was investigated using a single C-band (3.8-7.5 cm, 4-8 GHz) Synthetic Aperture Radar (SAR) from the Sentinel-1 satellite constellation (Dierking, 2013). The acquisition mode used was the Extra Wide mode Ground Range Detected Medium resolution (EW GRDM) which provided a definition of $40 \times 40 \mathrm{~m}$. The backscatter of the electromagnetic wave transmitted at horizontal polarization was received and decomposed into horizontal (HH) and vertical (HV) polarization components. Only the "less noisy" HH component was used in the present study (Dierking, 2010). These images allow us to detect changes in ice surface roughness and to characterize different sea ice types (e.g., landfast ice, drifting ice), and open ocean areas like cracks and leads. Dark grey areas, such as the ones observed near the study site, suggest smooth landfast sea ice that is not affected by rafting or ridges (bright grey). Two particular events were detected: (1) almost all sea ice was lost by mid-November 2014 compared with 2015; and (2) the sea ice broke up on 11 December 2014, and drift ice and open water areas appeared. A week later, almost no open water remained detectable and the sea ice was consolidated. 

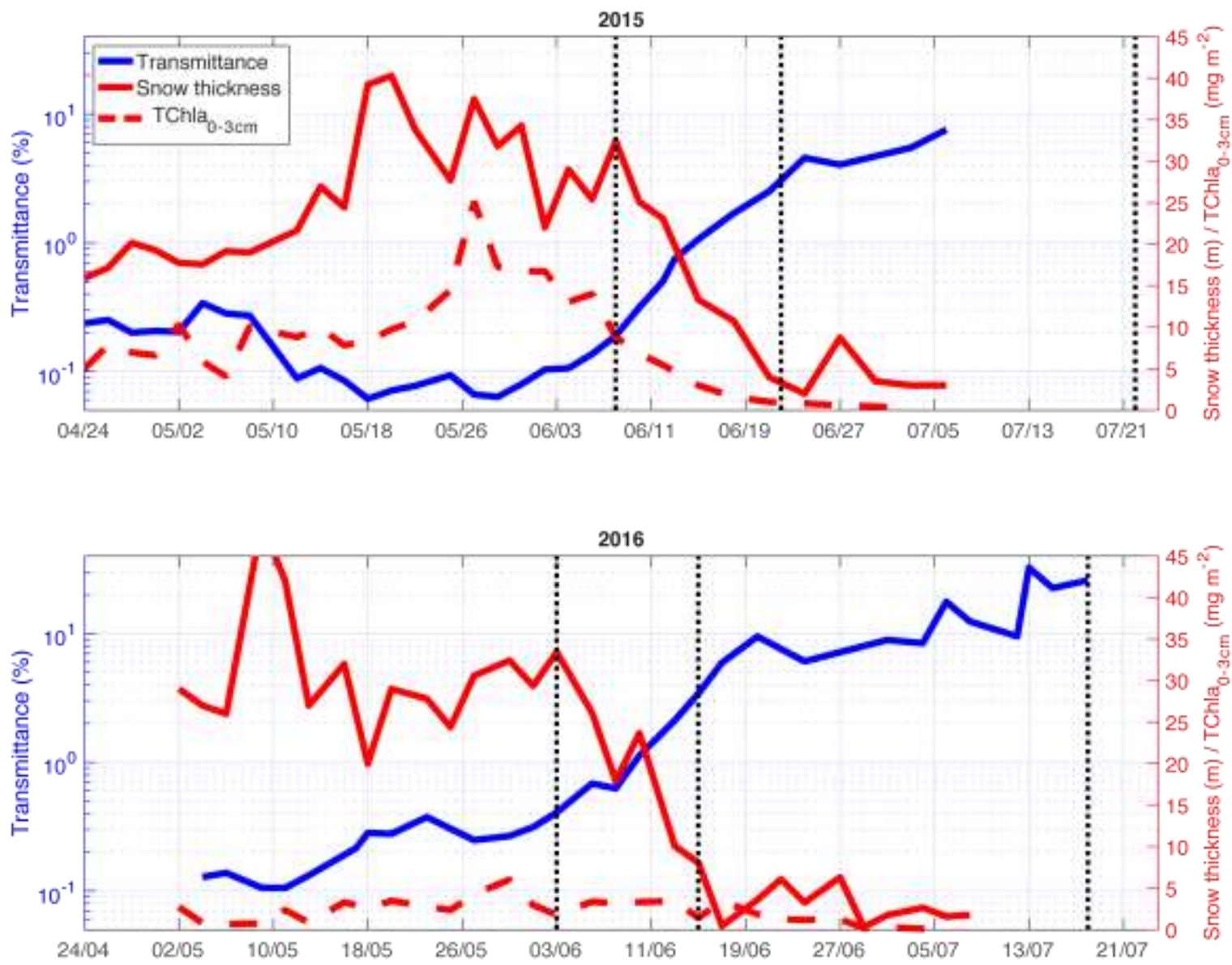

Figure S8. Time series of transmittance, snow thickness and ice algal concentration. For 2015 (top) and 2016 (bottom) time series transmittance (\%) was derived from daily PAR converted to $\mathrm{W} \mathrm{m}^{-2}$, and is shown together with snow thickness $(\mathrm{m})$ and ice algal concentration in the bottom 0-3 cm (TChl $a_{0-3 \mathrm{~cm}}, \mathrm{mg}$ $\mathrm{m}^{-2}$ ) of sea ice. Dates are day/month. 


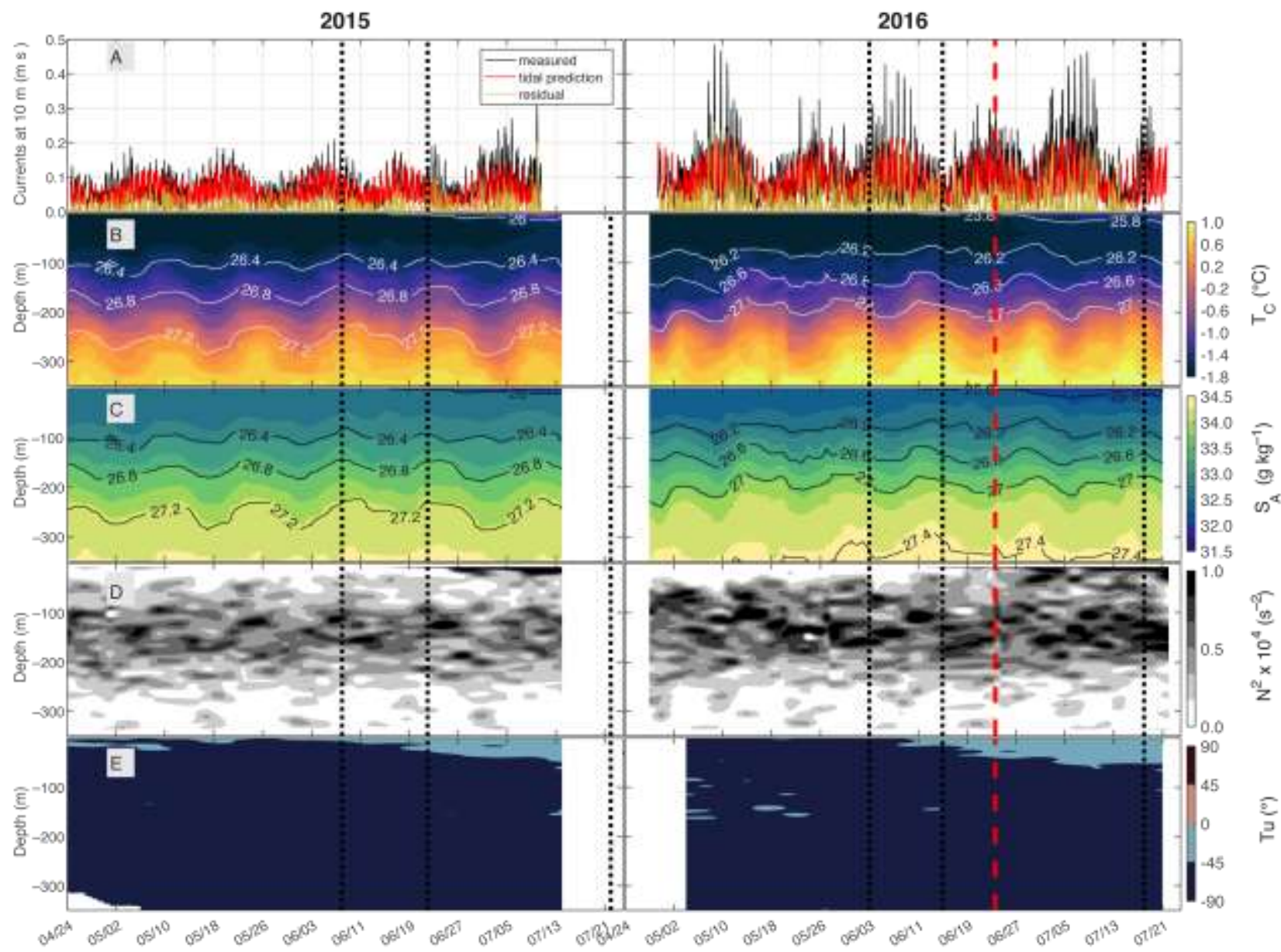

Figure S9. Hydrographic temporal evolution of the entire water column. Time series of (A) in situ current velocities at 10-m depth in black and predicted from harmonic analysis in red line, (B) conservative temperature $\Theta\left({ }^{\circ} \mathrm{C}\right)$ and $(\mathrm{C})$ absolute salinity $\mathrm{S}_{\mathrm{A}}\left(\mathrm{g} \mathrm{kg}^{-1}\right)$ fields with super-imposed isopycnals of potential anomaly density $\left(\mathrm{kg} \mathrm{m}^{-3}\right)$ in white lines. (D) Brunt-Väisälä frequency $\mathrm{N}^{2}\left(\mathrm{~s}^{-2}\right)$ and (E) Turner angle $\left(^{\circ}\right)$ until $340 \mathrm{~m}$. Turner angles $>0^{\circ}$ indicates that temperature is the main contributor to the density gradient whereas angles $<0^{\circ}$ indicate that salinity is the main contributor. Angles $<-45^{\circ}$ indicate that salinity is working against temperature. Vertical dotted lines chronologically represent snow melt initiation, melt pond initiation and sea ice breakup. The red dashed line indicates the date when turbulence was measured over a 13-h period. Dates are month/day. 

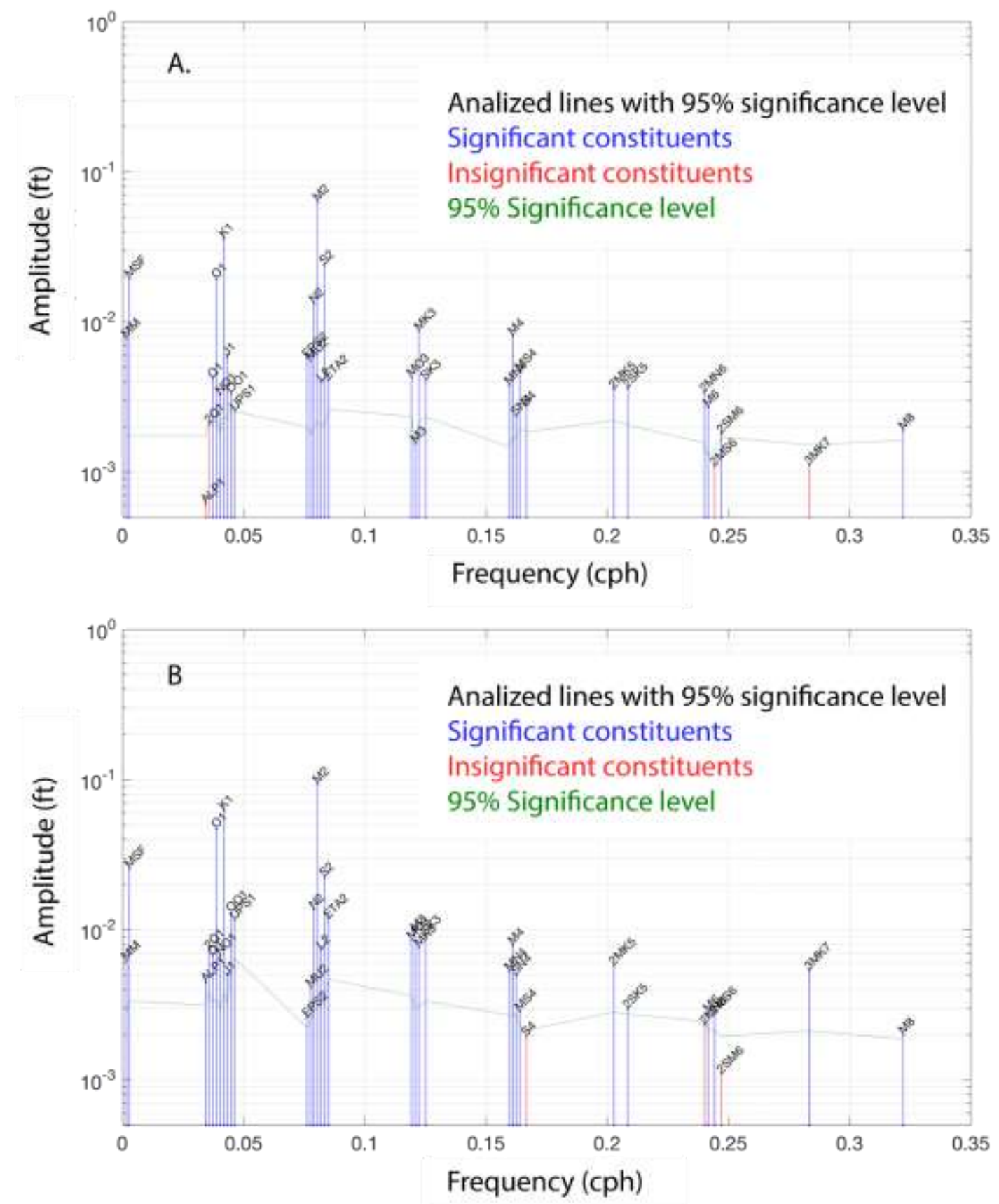

Figure S10. Characterization of the dominant tidal waves. Harmonic analysis of the current at $10 \mathrm{~m}$ for (A) 2015 and (B) 2016. Vertical lines indicate the main harmonic oceanic tidal waves associated with unique frequencies and amplitudes. Here, the M2 wave (period $=12 \mathrm{~h} 25 \mathrm{~min}$ ) dominates the tidal signal. 

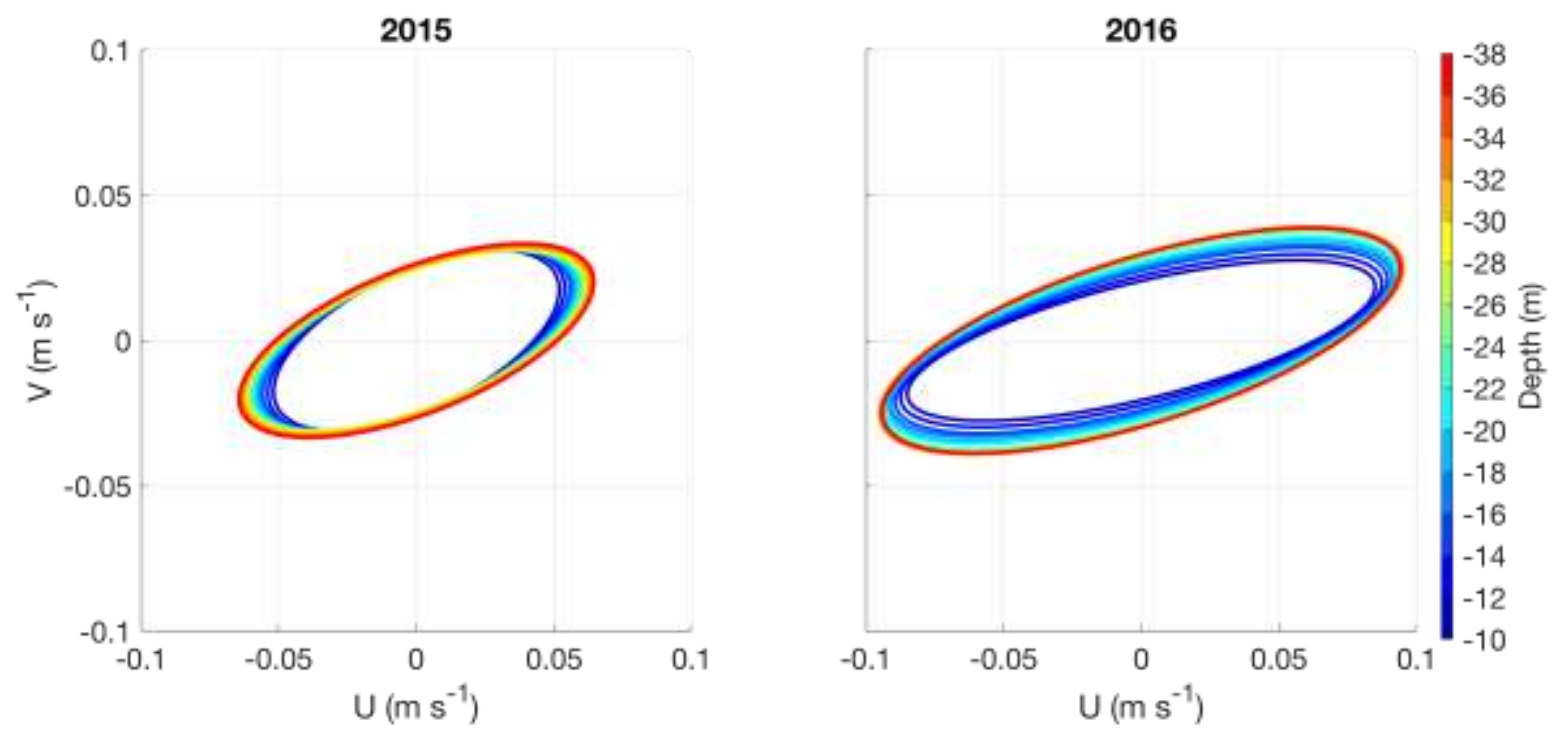

Figure S11. Depth evolution of tidal currents magnitude and direction. Tidal variance ellipses for both years (2015, left; 2016, right) at different depths from 10 to $38 \mathrm{~m}$ every $2 \mathrm{~m}$. The velocity constituent $\mathrm{U}$ (V) indicates the eastward (northward) direction. 

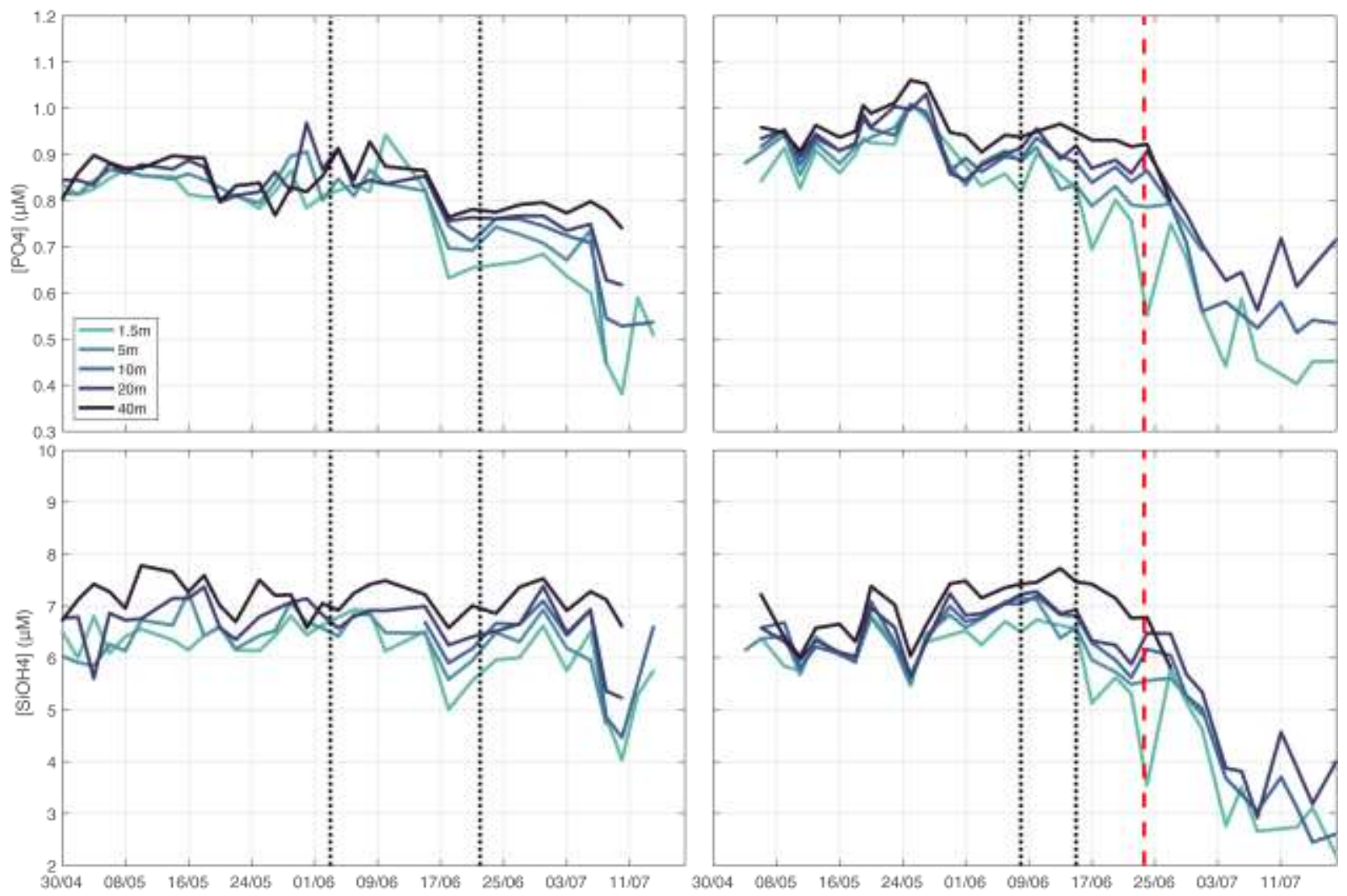

Figure S12. Temporal evolution of nutrients in seawater. Time series of phosphate and silicate concentrations in the water column for 2015 (left) and 2016 (right). Dates are day/month. 

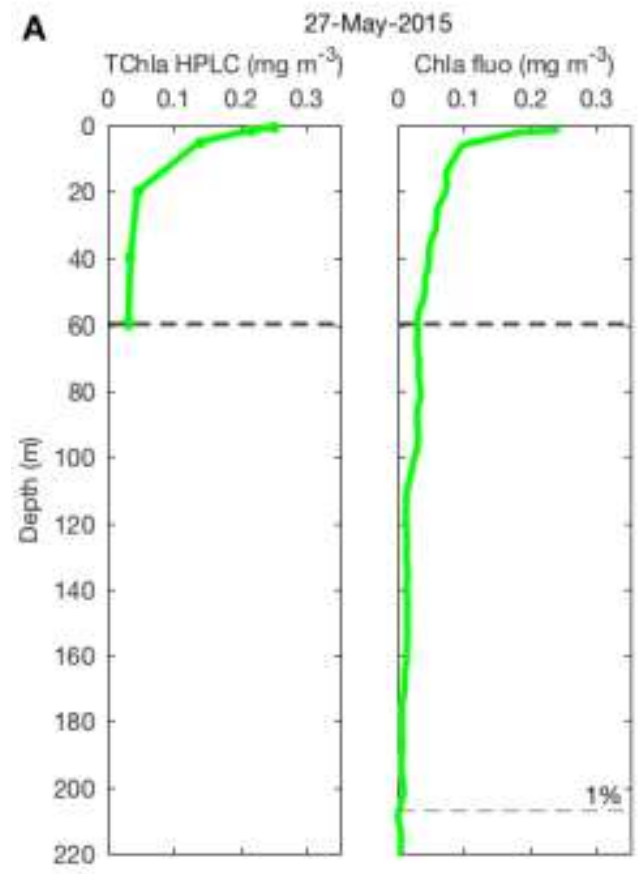

B
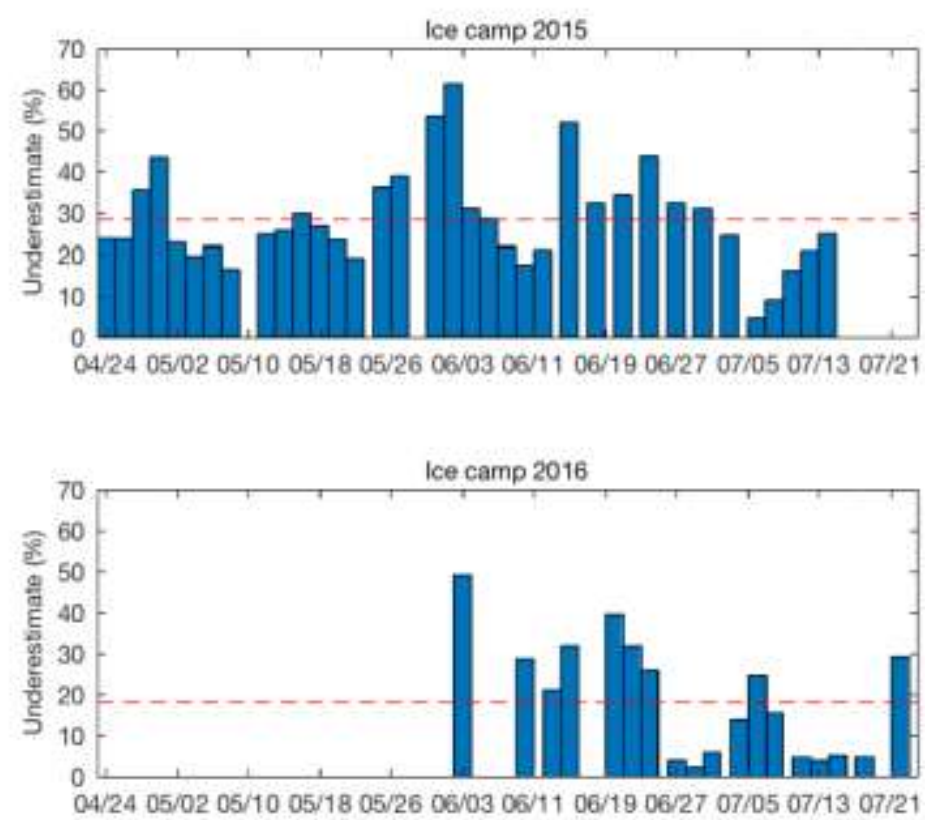

Figure S13. Estimation of the depth-integrated biomass bias from HPLC. (A) Example of a TChla profile from HPLC pigment data (left) and a Chla profile from a fluorometer (right) on 27 May 2015. The horizontal dashed black line marks the depth of the deepest TChla measurement, while the dashed grey line marks the depth where only $1 \%$ of the maximum value of the Chla profile remains. (B) Underestimate of biomass stock when the Chla is integrated down to the depth of the deepest TChl $a$ measurement rather than the depth of 1\% Chla, for 2015 (top) and 2016 (bottom). Horizontal dashed red lines mark the average underestimate. Dates in (B) are month/day. 

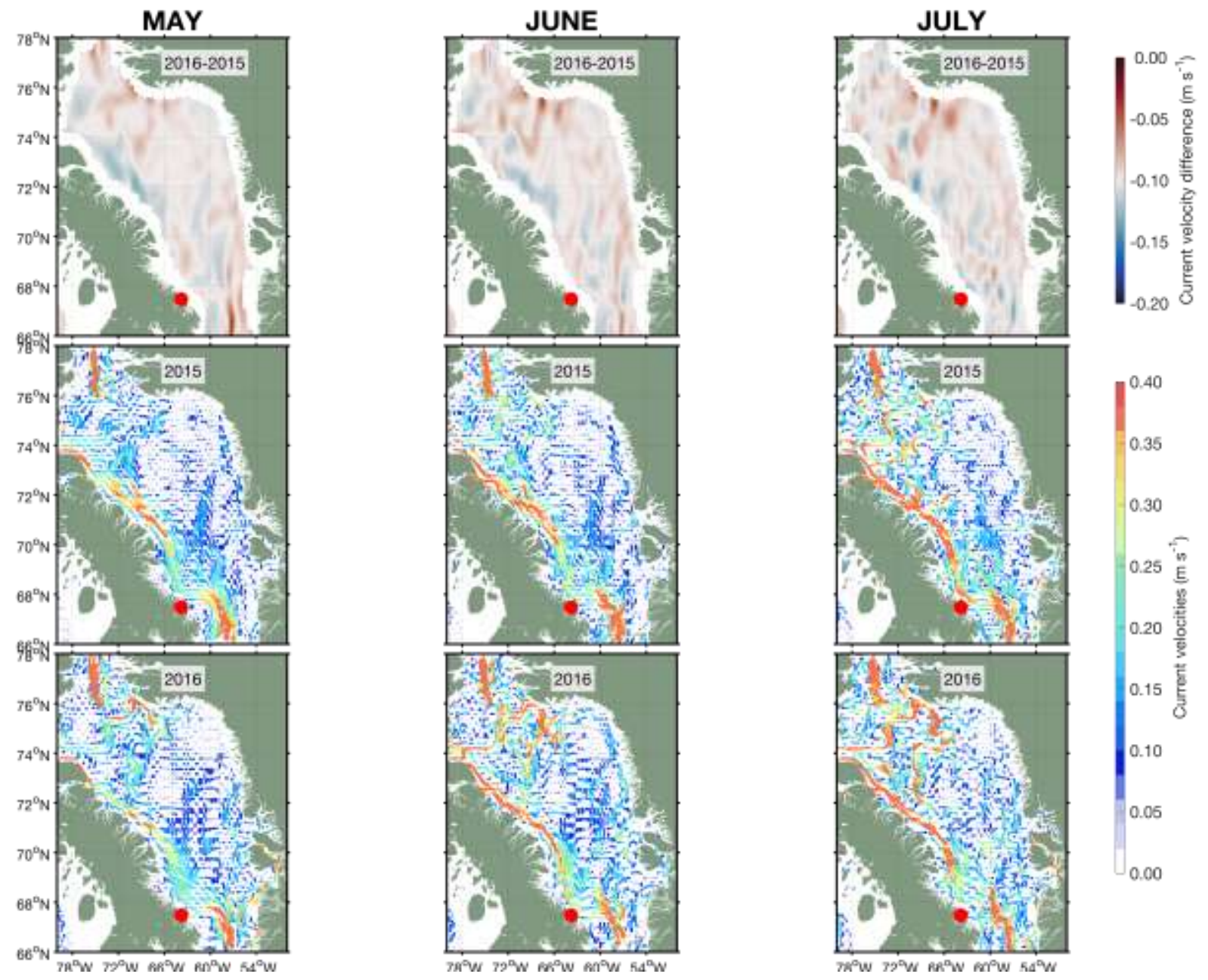

Figure S14. Modelled synoptic circulation in Baffin Bay. Monthly maps, May-July, of synoptic current velocity difference (top) and current velocities in 2015 (middle) and in 2016 (bottom) from reanalysis at 50 m (GLORYS12V, CMEMS http://marine.copernicus.eu, id = GLOBAL_REANALYSIS_PHY_001_030). Maps of current velocity difference are smoothed with a $72-\mathrm{km}$ standard deviation Gaussian filter to remove mesoscale activity. These maps are illustrating large-scale circulation differences between 2016 and 2015. The outflowing Baffin Island current (BIC) seemed to be more intense in 2016 carrying more Arctic Waters from Nares and Lancaster straits. 


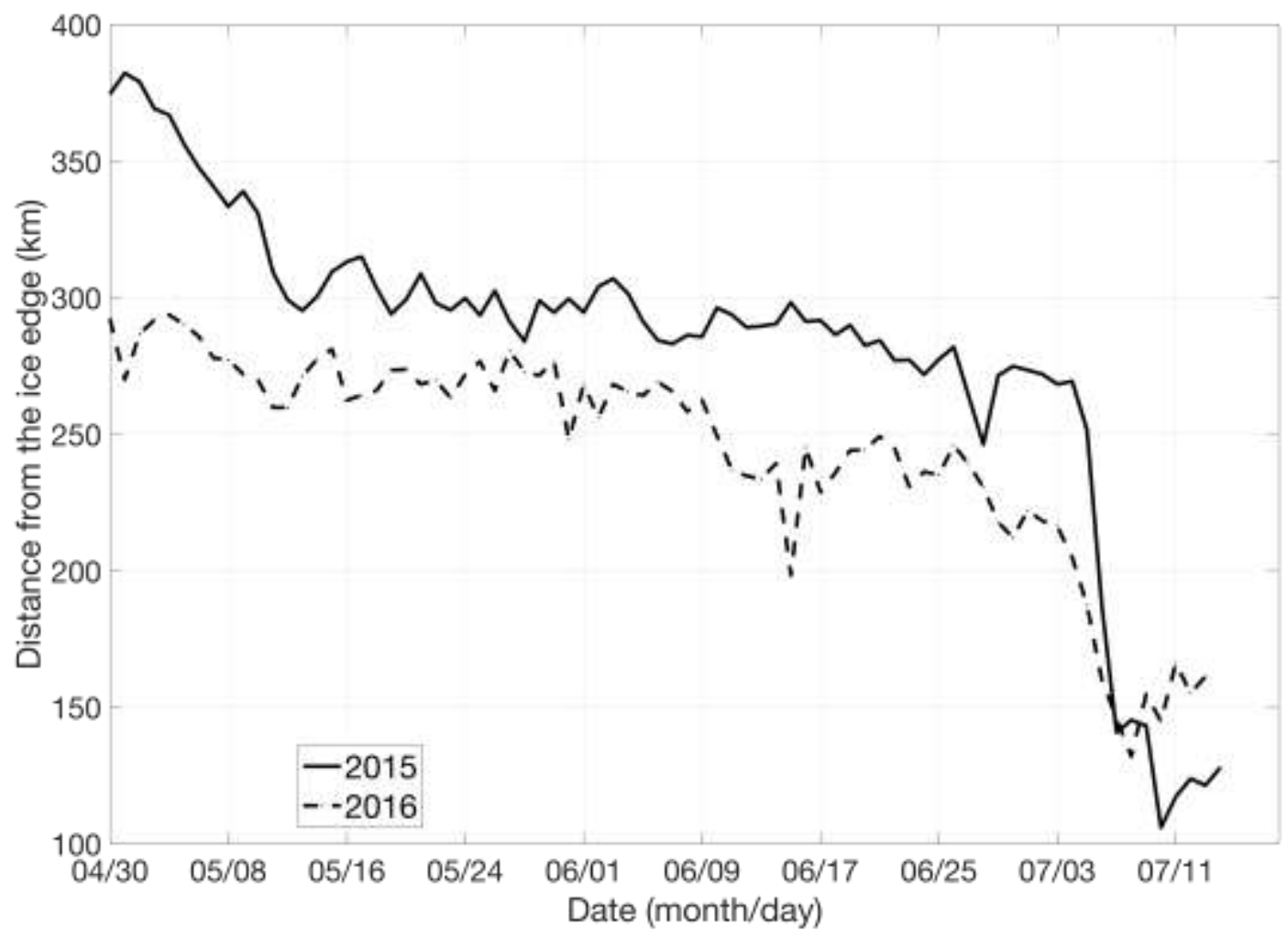

Figure S15. Closest distance between the study site and the sea ice edge. Sea ice edge was defined as sea ice concentration $=15 \%$. Dates are month/day. 


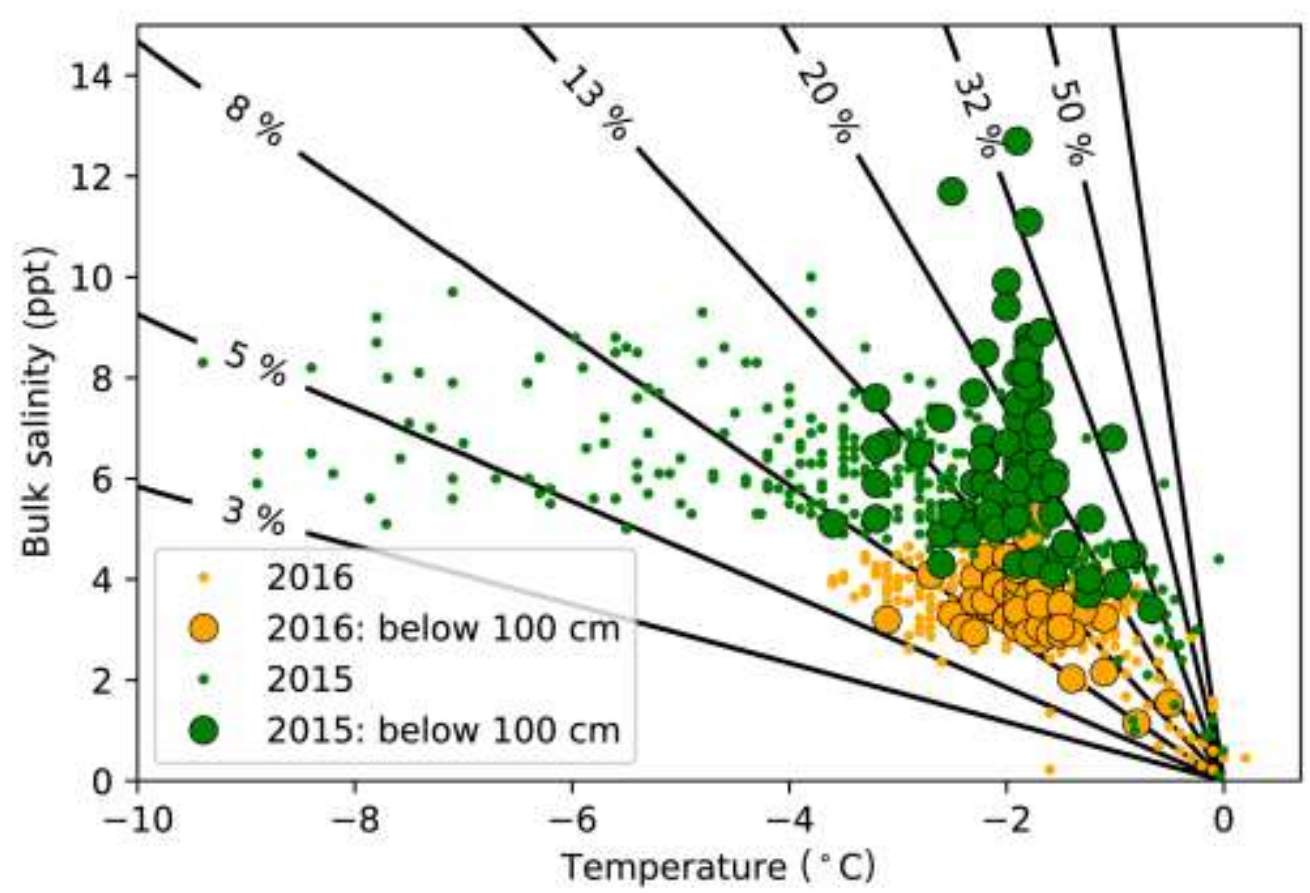

Figure S16. Bulk salinity against in situ temperature across all sections of all ice cores. The black lines are lines of constant brine volume (given as the percentage of the total volume that brines occupy). Year 2016 had remarkably higher temperatures, but the lower brine volumes observed at the bottom of the ice were due instead to differences in bulk salinity. 

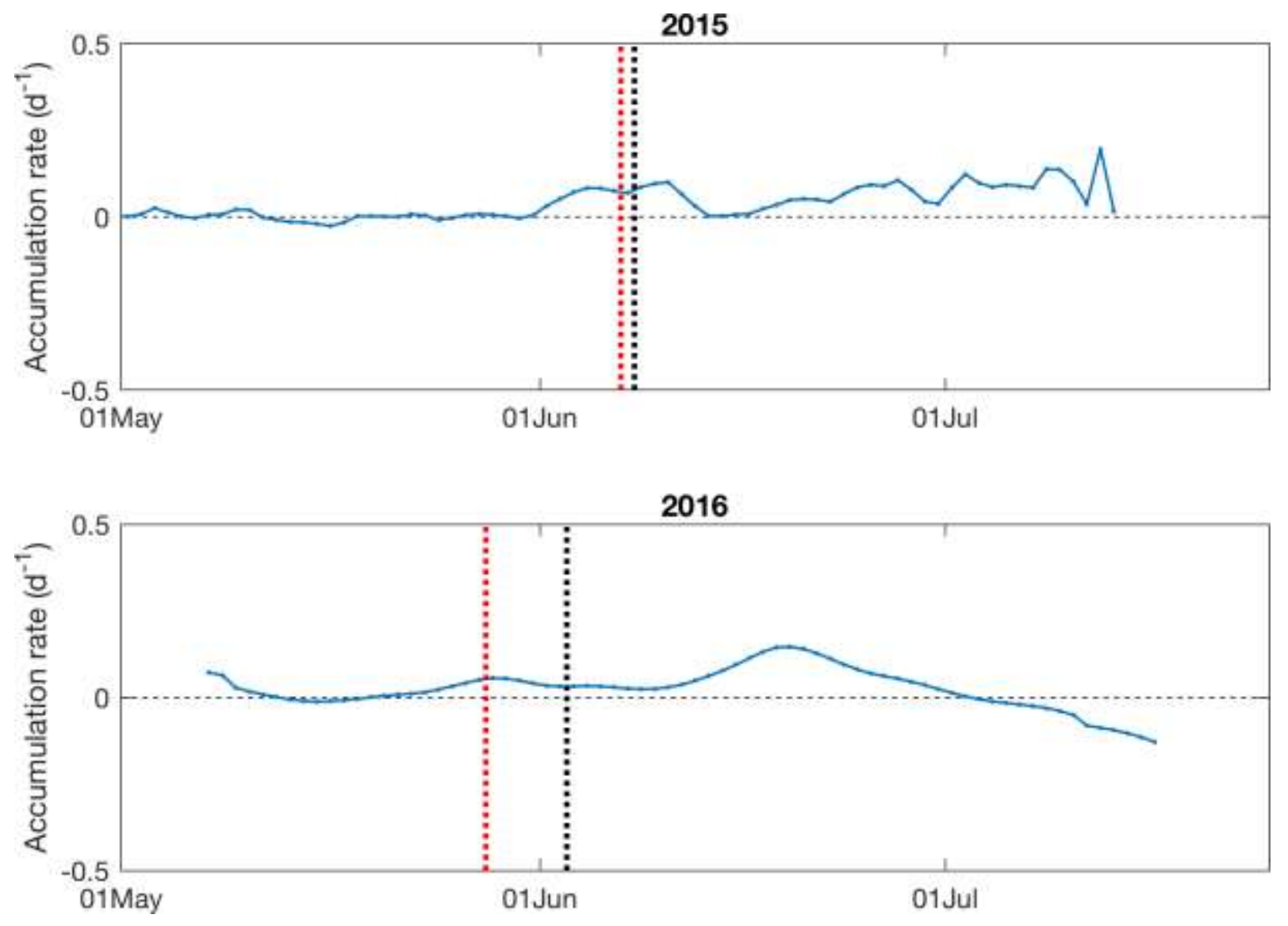

Figure S17. Phytoplankton accumulation rate. Accumulation rate $\left(\mathrm{d}^{-1}\right)$ was derived following the Boss and Behrenfeld (2010) calculation. The phytoplankton bloom initiation (vertical red dashed line) is identified when the accumulation rates are positive for one week. The snow melt onset is in black vertical dashed lines.

\section{References}

Dierking, W. 2010. Mapping of different sea ice regimes using images from Sentinel-1 and ALOS synthetic aperture radar. IEEE Transactions on Geoscience and Remote Sensing 48(3): 1,045-1,058. http://dx.doi.org/10.1109/TGRS.2009.2031806

Dierking, W. 2013. Sea ice monitoring by synthetic aperture radar. Oceanography 26(2): 100-111. http://dx.doi.org/10.5670/oceanog.2013.33 